\title{
DOCÊNCIA UNIVERSITÁRIA ON-LINE: CONCEPÇÕES PARA UM NOVO ESTILO DE PEDAGOGIA
}

\author{
ONLINE TEACHING AT HIGHER EDUCATION: conceptions for a new style of pe- \\ dagogy \\ ENSEÑANZA UNIVERSITARIA EN LÍNEA: conceptos para un nuevo estilo de la
pedagogía
}

Silvana Malusá

PhD em Educação. Vice-Diretora da Faculdade de Educação (Faced) da Universidade Federal de Uberlândia (UFU). Coordenadora Pedagógica DINTER/UFU/UNIFAP - Amapá. silmalusa@yahoo.com.br

\begin{abstract}
Mirna Tonus
Dra. em Multimeios. Coordenadora do Curso de Especialização Mídias na Educação. Professora do Programa de Pós-Graduação em Tecnologias, Comunicação e Educação (PPGCE) e do Curso de Comunicação Social: habilitação em Jornalismo da Universidade Federal de Uberlândia (UFU). Professora-jornalista e presidente do Fórum Nacional de Professores de Jornalismo (FNPJ). mirna@faced.ufu.br.
\end{abstract}

Igor Aparecido Dallaqua Pedrini Doutorando em Educação na Universidade Federal de Uberlândia (UFU). ia.pedrine@gmail.com

Carla Barbosa Alves Mestranda em Educação na Universidade Federal de Uberlândia (UFU). Pedagoga da Prefeitura Municipal de Uberlândia. carlabarbosa180@gmail.com

Ricardo Ferreira de Carvalho Mestrando em Educação na Universidade Federal de Uberlândia (UFU). Técnico de Editoração da UFU. riferreira@estadao.com.br

\begin{abstract}
RESUMO: A oferta de disciplinas on-line cresce vertiginosamente nas Instituições de Ensino Superior (IES) e os professores cada vez mais, se veem desafiado a modificar sua prática pedagógica para acompanharem a tendência vigente à modalidade de ensino não presencial. Diante desse problema, o objetivo deste trabalho - de natureza aplicada e exploratória e de abordagem qualitativa - é registrar as concepções de docentes universitários, atuantes em cursos de Pedagogia à Distância. Toma como foco compreender, sob a ótica desses docentes, o que é docência online, visando registrar e discutir as características necessárias para essa prática. Quanto aos resultados da pesquisa, verificou-se que as principais características podem ser agrupadas como sendo aquelas que: são capazes de entender o momento em que o aluno se encontra na relação ensino-aprendizagem fazendo as adaptações necessárias à comunicação com ele; que sabem distinguir os limites entre o ensino presencial e os do ambiente on-line; são conhecedores das ferramentas no Ambiente Virtual de Aprendizagem (AVA), bem como sabem planejar e mediá-las de acordo com a variação de estudantes e conteúdos; apresentam sempre um feedback sobre as atividades e solicitações dos aprendizes e, por fim, pensam os processos avaliativos específicos e têm abertura para o trabalho em equipe, ou seja, com outros profissionais envolvidos com o processo, que vão desde os produtores dos conteúdos até os tutores. PALAVRAS-CHAVE: Docência Universitária On-Line. Tecnologias da Informação e Comunicação (TIC). Ambientes Virtuais de Aprendizagem (AVA).
\end{abstract}

ABSTRACT: The offer of online courses soars on Higher Education Institutions (HEI) and teachers find themselves challenged, increasingly, to modify their pedagogical practice to follow up the trend towards online teaching modality. Faced with of this problem, the aim of this study - from applied and exploratory nature and qualitative approach - is to register the conceptions of university teachers in Pedagogy courses at Distance Learning. It takes as its focus the understanding, in the vision of these teachers, what is online teaching, aiming at record and discuss the necessary features for this practice. Regarding the results of the survey, it has been found that the main features can be grouped as being those that: are able to understand the moment of the student in the teaching-learning process making the required adjustments to the communication with him; Student knows how to distinguish the limits between classroom learning and the online environment; are knowledgeable in tools on Virtual Learning Environment (VLE) as well as to plan and mediate them, according to the variance of students and content; always submit feedback about activities and requests of apprentices and ultimately think particular evaluative processes and have opening for teamwork, ie, to other professionals involved with the process ranging from content producers to tutors .

KEYWORDS: University teaching online. Information and Communication Technologies (ICT). Virtual Learning Environments (VLE).

$\overline{\text { Artigo recebido em maio de } 2014}$

Aprovado em julho de 2014

Cad. Pes., São Luís, v. 21, n. 2, mai./ago. 2014 
RESUMEN: La oferta de cursos en línea crece dramáticamente en las Instituciones de Educación Superior (IES) y los maestros se ven desafiados, cada vez más, a modificar su práctica pedagógica para dar seguimiento a la tendencia a la modalidad de enseñanza en línea. Frente a este problema, el objetivo de este estudio - de naturaleza aplicada y exploratoria y abordaje cualitativo - es registrar las concepciones de los profesores universitarios en los cursos de Pedagogía en Educación a Distancia. Toma como foco entender, bajo la óptica de estos maestros, lo que es la enseñanza en línea, con el objetivo de registrar y analizar las características necesarias para esta práctica. Con respecto a los resultados de la encuesta, se ha encontrado que las principales características se pueden agrupar como aquellas que: son capaces de entender el momento del estudiante en el proceso de enseñanza-aprendizaje haciendo los ajustes necesarios en la comunicación con él; saber distinguir los límites entre el aprendizaje en el aula y el ambiente en línea; son conocedores de las herramientas en Entorno Virtual de Aprendizaje (EVA), así como para planificar y mediar en ellos de acuerdo a la variación de estudiantes y contenidos; siempre envían comentarios sobre las actividades y solicitudes de aprendices y en última instancia piensan particulares procesos evaluativos y tienen apertura para el trabajo en equipo, es decir, a otros profesionales que intervienen en el proceso que van desde productores de contenido a los tutores.

PALABRAS CLAVE: La enseñanza universitaria en línea. Tecnologías de la información y comunicación (TIC). Entornos de aprendizaje virtual (EAV). 
DOCÊNCIA UNIVERSITÁRIA ON-LINE | Silvana Malusá et al.

\section{1 | Introdução}

O docente universitário tem sido desafiado, cada vez mais, a modificar a sua prática pedagógica, pois a educação ganha novos significados, principalmente com os avanços tecnológicos que marcam o século 21. Assim, o acesso ao conhecimento tem-se dado das mais diferentes formas para além das aulas presenciais, modelo que perdura há muitos séculos, mas que, atualmente, é dividido com a Educação à Distância (EaD), uma forma de educação que acontece fora das tradicionais salas de aula, caracterizada, portanto, pela separação do professor e aluno no espaço e/ou tempo e que pode ser realizada pelo uso de diferentes meios, tanto impressos como eletrônicos.

Como o meio mais usual, atualmente, é o computador com acesso à internet, é comum a utilização dos termos EaD e Educação On-line como se tivessem apenas um significado, mas há pelo menos uma diferença entre eles: o segundo, é uma modalidade do primeiro, que tanto utiliza a internet para distribuir rapidamente as informações como pode fazer uso da interatividade por ela propiciada com o objetivo de concretizar a interação entre as pessoas. Interação que, no caso desta pesquisa, é estabelecida entre professores e alunos.

Pelas evidências deste estudo, percebe-se que existe um espaço não muito largo entre a EaD que já é praticada e a Educação On-line iminente nas Instituições de Ensino Superior (IES) no Brasil. A evolução necessária para o bom convívio entre os dois coloca a educação diante da necessidade de desenvolver práticas pedagógicas específicas, porque precisa ensinar em sintonia com as novas demandas provocadas pelo mundo on-line no que concerne à aquisição do conhecimento universitário. Assim, esta pesquisa, de natureza aplicada, exploratória e de abordagem qualitativa, registra as concepções de seis professores, atuantes em curso de Pedagogia à Distância, sobre a "docência universitária on-line" e, a partir delas, apresentar as características necessárias à prática pedagógica dessa docência.

A metodologia escolhida foi a entrevista, por tratar-se de uma técnica empregada sempre que os dados não são encontrados em registros e fontes documentais, mas que podem ser obtidos por meio de contatos pessoais. (CERVO; BERVIAN, 1996)

Para melhor contextualização dos resultados da pesquisa, apresenta-se, primeiramente, uma explanação do que vem sendo tratado sobre a docência universitária e a necessidade de uma formação emergente para esses docentes, que extrapolam o domínio da área específica, mas requerem um entendimento sobre didática e aspectos pedagógicos de fazer aula (ANASTASIOU, 1998). Em seguida, são apresentados os resultados da pesquisa com o intuito de estabelecer uma comparação entre as concepções dos professores universitários, que já atuam em EaD sobre a docência on-line e a literatura disponibilizada sobre essa temática.

\section{2 | DOCÊNCIA UNIVERSITÁRIA ON-LINE: aspectos gerais e seus desafios}

A educação tem sido um dos maiores desafios da sociedade contemporânea que está em constantes e rápidas transformações, panorama em que o docente precisa rever o seu perfil e atuação, bem como capacitar-se constantemente. Sob esses aspectos, segundo Malusá (2001), a educação tem sido considerada "a riqueza das nações" e, nesse contexto, o docente precisa ter clareza da sua prática e não apenas produzir/reproduzir os modelos aprendidos em sala de aula, o que exige uma reflexão sistemática e contínua.

Hoje, o momento histórico pelo qual passamos é composto por um cenário de rápidas transformações, onde, por exemplo, o pensamento ético é possuidor de uma pluralidade 
de perfis e tendências. Essa pluralidade atual de modelos éticos e o contexto socioeconômico global redefinem a finalidade e relevância da educação, a qual tem sido considerada a 'riqueza das nações'. (MALUSÁ, 2001, p. 26)

Nesse cenário, surge a necessidade de pensar e refletir sobre a formação profissional dos docentes e, em especifíco, os de nível universitário. A falta de formação docente desses profissionais (MASETTO, 1998), principalmente de cursos superiores de bacharelado, vem acontecendo ao longo da história. Dessa forma, não há como negar que a docência no ensino superior precisa ser refletida com mais intensidade, pois o que se constata, não raramente, são professores de professores, formadores de formadores. É preciso, então, repensar a atuação desse profissional, uma vez que apenas o domínio do conteúdo da área de conhecimento não é condição que garanta a capacidade de ensinar. O docente, então, tem que ter clareza da sua prática e conhecimentos sobre didática para que possa melhorar o seu desempenho em sala de aula. Como afirma Masetto (2003, p. 13, grifo do autor):

Essa situação se fundamenta em uma crença inquestionável até há bem pouco tempo mantida tanto pela Instituição que convidava o profissional a ser professor quanto pela pessoa convidada a aceitar o convite feito: QUEM SABE, AUTOMATICAMENTE SABE ENSINAR. Mesmo porque ensinar significa ministrar aulas expositivas ou palestras sobre determinado assunto dominado pelo conferencista, mostrar na prática como se fazia; e isso um profissional saberia fazer.

Ainda, complementa o autor:

Só recentemente os professores universitários começaram a se conscientizar de que seu papel de docente do ensino superior, como o exercício de qualquer profissão, exige capacitação própria e específica que não se restringe a ter um diploma de bacharel, ou mesmo de mestre ou doutor, ou ainda apenas o exercício de uma profissão. Exige isso tudo, e competência pedagógica, pois ele é um educador. (MASETTO, 2003, p. 13)

A relação no processo ensino e aprendizagem requer envolvimento de professores e alunos, a compreensão de que não haverá aprendizagem sem uma ação em equipe que exige corresponsabilidade de seus participantes. Por isso, Masetto (2003) afirma que deve haver um relacionamento entre professores e alunos que possibilite a troca de experiências, levando à verdadeira construção do conhecimento. Como isso é possível, entretanto, sem uma formação específica do docente universitário? Nos cursos presenciais, a ação de ensino é focada em momentos de encontro face a face
entre alunos e professor e os recursos telemáticos podem ser um complemento ou um
recurso de ensino potencializador de certas aprendizagens. O EaD implica na separação
espaço temporal entre aluno e professor cujo modelo comunicacional, ao longo da
história dela, priorizou os meios de comunicação de massa (mídia impressa, rádio, TV) e
mais recentemente a comunicação online. As práticas de EaD frequentemente centram
sua concepção pedagógica no auto aprendizado ou no estudo individualizado sustentado
modestamente por tutores e materiais de apoio muito mais na função de 'tira-dúvidas'.
(CALIXTO, 2012, p. 43)

A educação, hoje, está mergulhada em uma sociedade da informação, uma sociedade em rede, permeada por tecnologias em constante evolução e mudança. Portanto, as Tecnologias de Informação e Comunicação (TIC) não são simplesmente ferramentas a serem aplicadas, mas processos a serem desenvolvidos. Eis aí mais um, entre tantos outros desafios para o docente 
DOCÊNCIA UNIVERSITÁRIA ON-LINE | Silvana Malusá et al.

universitário: o trabalho com a docência on-line, que assume um papel importante na educação, não poderá mais ser ignorada:

Educação on-line pode ser definida como o conjunto de ações de ensino- aprendizagem que são desenvolvidas através de meios telemáticos, como a Internet, a vídeo conferência e a teleconferência. A educação on-line acontece cada vez mais em situações bem amplas e diferentes, da educação infantil até após-graduação, dos cursos regulares aos cursos corporativos. [...] A educação on-line não equivale à educação a distância. Um curso por correspondência é a distância e não é on-line. Por outro lado, não podemos confundir a educação on-line só com cursos pela Internet e somente pela Internet no modo texto. (MORAN, 2003, p. 41)

A educação não é neutra, por isso, requer que o docente trabalhe a relação do homem com a sua realidade de maneira planejada e organizada durante a aula. Assim, o docente universitário precisa estar em contínuo aperfeiçoamento para a sua formação pedagógica. O papel dele é contribuir significativamente na formação de um aluno que saiba refletir, tomar decisões, ser crítico e autônomo. Essa atuação, então, solicita maior atenção na relação humana/interações na prática docente (cognição e afetividade devem caminhar juntas). No caso da Educação On-line:

A Educação Online, como concebida nesta investigação, traz implícita uma proposição pedagógica específica voltada para a interação e colaboração suportadas pelos recursos online. A proposição pedagógica e comunicacional dela está centrada na interação. Tal percepção imprime à docência online um caráter particular em relação ao que poderemos chamar de ensino tradicional. (CALIXTO, 2012, p. 45)

As TIC já são realidades desde as últimas décadas do século passado, chegando ao espaço educacional com força total. Não há mais como o professor fugir da discussão relacionada à Educação On-line. É exigido um novo perfil desse docente, necessitando estar para além da prática pedagógica voltada a um paradigma tradicional de educação, tentando reproduzi-lo em rede.

A educação on-line está em seus primórdios e sua interferência se fará notar cada vez mais em todas as dimensões e níveis de ensino. Como avanço da telemática, a rapidez de comunicação por redes, a facilidade próxima de ver-nos e interagir a distância, a educação on-line ocupará um espaço central na pedagogia nos próximos anos. (MORAN, 2003, p. 42)

Nesse cenário, o docente universitário precisa estar atento às questões voltadas à velocidade de circulação do conhecimento que está sendo produzido, bem como as diferentes formas de conhecer por meio das TIC e dos Ambientes Virtuais de Aprendizagem (AVA). A maioria dos estudantes, por exemplo, tem acesso às TIC e utiliza tais ferramentas para se comunicar e informar. Desse modo, de acordo com Parreira Júnir, Malusá e Oliveira (2013), os docentes precisam de capacitação e incentivo para usar esses recursos em sala de aula. Usar blogs, vídeos, hiperlinks, chatsee-mails, entre outros recursos, já é realidade nas universidades e, para muitos professores, tanto na modalidade presencial quanto em cursos à distância.

A Educação Online implica num modelo diverso do usual de docência e que, portanto, requereria papéis novos ao professor. Contudo, não há tanto ineditismo nas funções apresentadas como se verá a seguir. Frequentemente é possível uma correspondência como modelo tradicional sem que com isso se reduza a docência online à docência presencial ou tradicional. (CALIXTO, 2012, p. 46) 
Portanto, o maior compromisso do docente é relacionar teoria e prática, através do tripé do ensino superior: ensino, pesquisa e extensão. Essa relação direta entre teoria e prática apresenta qual visão/concepção do professor sobre homem, mundo e educação; o entendimento sobre o que é avaliar e como define os objetivos do seu trabalho. Nesse sentido, as IES precisam assumir o compromisso com a prática/formação pedagógica dos seus profissionais, apresentando propostas de formação e capacitação/atualização em serviço.

A formação e capacitação do docente universitário devem contar com um currículo amplo, específico e flexível, tendo como foco a formação técnica, política, humana e pedagógica desse docente. Há de repensar-se a lógica das IES no sentido de investir em políticas públicas que de fato democratizem a educação. Sendo assim, é imprescindível criar espaços e momentos de trocas e de discussões democráticas para se repensar a educação como ferramenta, que forma seres humanos e não apenas máquinas para o sistema mercadológico. (MALUSÁ, 2001)

A ressignificação do mundo, frente à velocidade assustadora das informações, impede que o docente, em especial, o universitário, ignore a Educação On-line. De acordo com Vilarinho e Ganga (2009), a inclusão das tecnologias no processo ensino e aprendizagem pode causar uma "ruptura" com a "ambiência comunicacional", exigindo do professor novas práticas colaborativas que extrapolem as vivências tradicionais que são dadas às situações educacionais, ainda com ênfase na transmissão de conteúdo. Essa nova postura exigida diante das tecnologias, que também estão presentes no espaço educacional em constante transformação, faz com que o docente universitário necessite rever a sua postura diante do conhecimento e do aluno.

O propósito em discutir e refletir sobre a docência universitária e, consequentemente, sobre prática pedagógica, visando aspectos que influenciam diretamente no processo ensino e aprendizagem, presencial ou on-line, tem sido algo eficaz e que tem gerado uma nova visão do docente. Essa prática pedagógica, de acordo com Masetto (2003), deve estar intimamente relacionada ao Projeto da Instituição, ao Projeto Pedagógico do Curso, ao Planejamento das Séries e das Disciplinas e Planejamento para Docência, Projetos de Pesquisa e Projetos de Extensão. Diante dessa organização e planejamento, o docente universitário tem delineado o seu percurso de trabalho e, principalmente, definido as suas concepções de homem, mundo, sociedade e educação. Ainda para o autor, no plano individual, o docente precisa acreditar no que sabe fazer bem como professor.

A Educação On-line tem avançado por meio das plataformas virtuais, que potencializam a relação professor-aluno na aprendizagem dos conteúdos. Os Ambientes Virtuais de Aprendizagens - AVA, de acordo com Vilarinho e Ganga (2009), seguem um dos princípios básicos da educação, que é a flexibilidade na realização das atividades, respeitando o ritmo próprio a cada aluno. Os recursos desses ambientes são os mesmos usados na internet e demandam professores com posturas bem distintas das que se encontra na educação presencial com enfoque tradicional. É válido destacar que esses ambientes podem ser usados tanto em processos totalmente on-line, como em atividades semipresenciais ou até mesmo como apoio na sala de aula convencional. Os AVA que se destacam no cenário nacional são o Teleduc e o Moodle. A utilização desses ambientes virtuais exige novos papéis para os professores que de fato assumem a Educação On-line.

Ampliar o olhar para a docência on-line é importante e exige uma nova construção do conhecimento e um perfil de professor ressignificado. Vários desafios e alguns empecilhos são apontados durante um curso on-line. Por isso, é válido destacar que um bom curso só atingirá os seus objetivos se contar com alunos curiosos e professores comprometidos com o processo de formação, que discutam questões da prática e da vivência, compartilhando as experiências com o intuito de enriquecer as discussões e o aprendizado. O que conta em um curso, seja presencial ou a distância, é a aprendizagem significativa que ele promoverá. 


\begin{abstract}
Refletir sobre a docência on-line e sua importância, enquanto prática educativa/social é algo imprescindível, pois os fenômenos sociais estão cada vez mais dinâmicos e os indivíduos necessitam de mecanismos para acompanhar esta dinamicidade. Para a docência, seja ela online e/ou presencial, não é suficiente dar ênfase apenas na aquisição de novos conceitos e conteúdos, fazendo-se necessário uma política de planejamento contínuo e integrado, adequado ao processo de transformação social e vinculado ao surgimento das Tecnologias da Informação e da Comunicação na Educação -Tice. (FERREIRA; SILVA, 2009, p. 5648)
\end{abstract}

Nesse sentido, a docência on-line é uma prática educativa e, portanto, requer trabalho intenso na diversidade que se apresenta. O profissional que se dedica a ela deve estar atento às diferenças entre a docência presencial, pois ela requer interatividade e colaboração, não podendo estar calcada simplesmente nas ferramentas da tecnologia digital. Portanto, há de compreender, de fato, qual é o perfil do docente on-line e as características necessárias para a sua atuação.

\title{
3 | APRESENTANDO E DISCUTINDO A PESQUISA
}

A pesquisa teve por objetivo articular as concepções de docência universitária on-line, bem como as características necessárias à prática pedagógica de professores que atuam em cursos de Pedagogia à distância. Por conta disso, o método para realização deste trabalho está embasado na pesquisa qualitativa, norteado por Triviños (1987), Minayo (2003) e Flick (2009).

Considerando o ambiente on-line em que atuam os sujeitos, as questões da pesquisa foram enviadas por e-mail a dez professores que lecionam em cursos de educação à distância. Trabalhou-se com entrevista estruturada, que é "quando um entrevistador usa um esquema de questões sobre um determinado tema, a partir de um roteiro (pauta), previamente preparado". (PÁDUA, 2004, p. 70)

$\mathrm{O}$ instrumento de pesquisa contou com dois grupos de questionamentos. O primeiro, estava alicerçado sobre a concepção que cada entrevistado tinha sobre a docência on-line; o outro, grupo de questões se preocupava em conhecer as características que os sujeitos atribuíam à docência on-line. Seis sujeitos responderam à solicitação. Para efeito de assegurar a identidade de cada um dos participantes, optou-se, aleatoriamente, cunhar a cada sujeito um número, de um ao seis.

O primeiro grupo de questões buscava trazer à tona como cada sujeito conceituava a docência on-line. Por um lado, com um olhar superficial às respostas, percebeu-se que eles concordavam, pelo menos cinco deles, com o fato de a docência on-line ser uma modalidade mediada pela tecnologia da comunicação e informação. Isso é expresso nos seguintes fragmentos:

S1: Ser professor através de alguma mediação tecnológica;

S2: [...] atividades de gestão por meio de suporte tecnológicos em espaços virtuais;

S3: [...] desenvolvida por meio das tecnologias da comunicação e informação;

S5: [...] o exercício docente em determinado curso pela internet;

S6: [...] uma atividade da docência de educação a distância, a qual desenvolve o processo de ensino e aprendizagem através do AVA - Ambiente Virtual de Aprendizagem que é a sala de aula da EAD [educação a distância] que disponibiliza na internet.

Entretanto, a concepção embasada no conceito da docência, por meio da mediação, induz agrupar a análise dos resultados sob duas categorias - talvez cabal para todo este trabalho sendo uma ligada a um ensino instrumentalizado e, por isso, com uma concepção tradicional e, a outra, não tradicional, com foco na interação.

A primeira delas reside no que mostram Silva e Claro (2007, p.88), quando refletem sobre os 
DOCÊNCIA UNIVERSITÁRIA ON-LINE | Silvana Malusá et al.

saberes necessários para a docência on-line, no momento em que abordamos saberes advindos da comunicação, quando, então, ponderam:

No entanto, muitas vezes falta aos professores o tratamento adequado da comunicação, de modo que se permita efetivar a materialidade da ação interativa em lugar da transmissão e da memorização. Mesmo inspirados nos excelentes autores, os professores permanecem apegados à transmissão porque não desenvolveram uma atitude comunicacional que favoreça as interações e a dialógica na aprendizagem.

Ao apontar a ausência de uma competência comunicacional entre os docentes de cursos online, entendida como um elemento imprescindível para uma docência baseada na mediação tecnológica para o desenvolvimento da aprendizagem, os autores revelam que os professores a suprimem se agarrando aos modelos tradicionais de aprendizagem, com base em transmissão e memorização.

Por isso, uma das categorias de análise reside no fato de os professores usarem da mediação com uma abordagem tradicional do ensino. Assim, temos respostas como estas:

S1: O ofício central da docência está presente e é fundante, ele [o professor] terá um (ou mais) instrumentos mediadores desse processo de ensino- aprendizagem.

S2: É a realização do trabalho de um profissional da educação que possa envolver a ação docente [...] que no Brasil está associada às plataformas de aprendizagem.

Embora a fala desses sujeitos pareça centrar-se apenas na mediação, aponta o professor como o possuidor dos instrumentos mediadores; algo parecido com a perspectiva do S4: "Mais uma forma, dentre tantas outras, de ensinar ao outro".

As três visões despejam sobre os ombros do professor a responsabilidade de interagir e ensinar, descartando a dupla via de comunicação presente no processo de ensino-aprendizagem.

Para Gil (1997, p. 25), a perspectiva tradicional "vê os alunos como instrumentos passivos, capazes de aprender e aceitar orientações, mas muito imaturos para iniciar qualquer atividade significativa". Por essa perspectiva, o ensino-aprendizagem é centrado no professor e o aluno apenas executa as prescrições que lhes são fixadas.

É evidente que essa é uma postura que se pretende para a boa prática do ensino-aprendizagem abandonar na docência on-line. Portanto, "requer de nós uma outra postura no que se refere à docência, afim de não reproduzir, em cursos on-line ou presenciais, a mesma dinâmica de aula fundamentada na lógica do "falar/ditar", instruir/repetir mecanicamente". (FERREIRA; SILVA, 2009, p. 5648)

A segunda categoria para análise das respostas foge, então, dessa dinâmica e:

- rompe com a lógica comunicacional do falar/ditar, um/todos;

- rompe com o paradigma educacional positivista, que separa e dissocia o professor do aluno, o texto do contexto;

- rompe como poder/saber centralizado apenas no professor;

- rompe com a educação bancária, a lógica disciplinar e individualizada;

- questiona a idéia de cursos de Educação à distância fundamentados no instrucionismo.

(SACRAMENTO; SONNEVILLE, 2008, p. 181)

A outra proposta de análise se fundamenta em uma docência on-line que irá permitir a interação entre professor e aluno, fugindo de um ensino meramente instrucionista. Essa postura está presente na fala dos sujeitos: 


\begin{abstract}
S3: Prática profissional que rompe com a mera transmissão-repetição de conteúdos, que tem por finalidade desenvolver a mediação pedagógica (conteúdo-aluno), a formulação de questionamentos e sistematização de experiências.

S5: [...]Uma forma de agir interativamente.

S6: Esta interação[professor e aluno] pode acontecer de forma dinâmica através de ferramentas digitais assíncronas (fóruns,vídeo aulas, hipertextos) ou síncronas (chats,web conferência).
\end{abstract}

Para análise do segundo grupo de questionamentos, optou-se por continuar com a perspectiva de ensino tradicional e ensino não tradicional na esfera da docência on-line. O motivo se deu pela necessidade de verificar a presença ou não de contradições nas respostas dos sujeitos ao responder às duas questões, bem como apontar e relacionar as características necessárias aos professores em cada uma das categorias. Conforme Almeida (2006, p. 101-2), um professor que, no ensino presencial, se utilize de uma abordagem tradicional, fará uso dela também no ensino on-line.

Quando questionados sobre as características necessárias ao docente on-line, aqueles mesmos sujeitos que foram abarcados na categoria do ensino tradicional (a saber sujeitos: 1, 2 e 4), responderam:

\begin{abstract}
S1: Assumir [...] uma visão de sujeito, conhecimento, realidade/contexto que contribua para processos de ensino e de desenvolvimento. Não é simplesmente transferir o que é trabalhado na modalidade presencial para a mediação tecnológica, mas adaptar linguagem, maneiras e formas.

S2: Conhecimento do ambiente virtual no qual processará a ação; compreensão e clara distinção entre espaços educativos virtuais e espaços educativos presenciais; [...] noções de interação e processos de planejamento neste tipo de ambiente; compreensão do tipo e forma de linguagem a ser trabalhada no ambiente [...] considerando a variação dos estudantes; intencionalidade do componente curricular.

S4: [...] curiosidade e intimidade em relação aos recursos tecnológicos [...] certo desprendimento em relação ao espaço escolar.
\end{abstract}

Dentre as respostas dos sujeitos, duas perspectivas se destacam. Uma é marcada pela distinção dos espaços de aprendizagem presencial e à distância. A outra diz respeito à necessidade do docente adaptar-se à linguagem, que deve ser trabalhada no ambiente on-line.

Essas duas perspectivas não são capazes de revelar o rompimento com a prática tradicional de ensino. São instigantes, pois evidenciam a percepção de mudança do espaço da aprendizagem, requerendo a transformação do domínio da linguagem do professor. Talvez resida nas falas dos sujeitos o que Silva e Claro (2007) chamem de atitude comunicacional que, na visão deles, é a base de um caminho para se fugir do ensino tradicional na Educação On-line.

Embora se possa configurar aqui uma contradição entre ser e não ser educação tradicional, a fala dos sujeitos aponta para um processo de ruptura com essa forma de ensinar. Essa peculiaridade não é capaz de inscrever se essa transformação realmente vai ou não acontecer, apenas assinala o seu curso dentro da prática dos sujeitos entrevistados.

O segundo conjunto de sujeitos entrevistados, aqueles classificados na categoria de ensino não tradicional, disseram:

S3: [...] Desenvolver práticas de interação e socialização diversificadas que envolvam os aprendizes no processo, pensar e planejar ações que atendam as características da educação on-line, dar feedback imediato para as solicitações e necessidades do aprendiz, pensar processos avaliativos específicos para a modalidade. 


\begin{abstract}
S5: [...] o Professor on-line precisa apresentar as características pedagógicas do saber ensinar utilizando-se das ferramentas didáticas adequadas, precisado saber comunicar-se por escrito e verbalmente quando for ocaso (aulas gravadas etc.), precisa ser empático com os alunos por meio dos textos, da ação e reação (feedback) no tempo adequado. S6: O professor que aceita o desafio de participar de cursos a distância precisa estar aberto para realizar um trabalho em equipe já que, no EAD, há a poli docência e a necessidade da constante colaboração do setor tecnológico para organizar o conteúdo e as atividades de ensino no AVA. [...] Se o docente on-line for um tutor, ele deve estar atento para as dúvidas dos alunos procurando respondê-las no menor prazo possível e assim evitar que o aluno desista do curso por dificuldade ou isolamento.Também incentivar os alunos a interagirem no AVA através das atividades propostas pelos professores, de maneira que consigam apropriar-se crítica e profundamente do conteúdo estudo. Além disso, o tutor deve ser protagonista do curso, ou seja, além de participar da execução das atividades propostas pelo professor conteudista, sugerir alterações, acréscimos, complementações, lembrando que estas devem ser negociadas como professor responsável pela disciplina.
\end{abstract}

Os fragmentos das respostas apontam que o professor deve saber interagir, socializar e ter empatia com os alunos, isto é, recobrir a mediação de afeto.

A interação acontece de forma mais significativa, não quando simplesmente os recursos tecnológicos estão disponíveis, mas quando a afetividade está articulada no processo. Assim, para a efetivação da aprendizagem é essencial a construção de vínculos na relação pedagógica entre todos os envolvidos e um contexto que propicie problematizações e discussões entre alunos e professores. (NETTO, 2006, p. 52)

Assim, dentro de um ensino não tradicional na esfera da Educação On-line, o afeto e a construção de vínculos é um dos caminhos para realização da aprendizagem. Esse afeto deve acontecer na relação entre alunos e alunos, professores e professores e professores e alunos.

\title{
4 | CONSIDERAÇÕES FINAIS
}

A investigação desta pesquisa aponta para existência de uma situação paradoxal. Mesmo considerando que o conhecimento nunca esteve tão ao alcance das pessoas como hoje, frente às diversas formas de comunicação instantânea, os mesmos meios de comunicação que podem servir para a democratização do conhecimento estão a serviço da mídia da sociedade de consumo, criando, muitas vezes, necessidades superficiais nas pessoas. A sedução para o consumo faz com que o ser humano se torne manipulável e que seja explorado em sua anestesiada fragilidade. As chances que ele tem de alterar tal quadro são encontradas no universo do conhecimento, possibilitando-Ihe melhores e mais sábias escolhas.

Em meio à existência de uma turbulência generalizada frente ao "ouro moderno", o conhecimento, é que se optou por uma reflexão frente às concepções de docência universitária on-line. Pautou-se, portanto, por dois problemas básicos: 1. Quais as concepções de professores universitários sobre docência universitária on-line? 2. Quais as principais características, na ótica desses professores, necessárias a uma prática pedagógica mais eficiente?

Ao analisar as respostas ao primeiro questionamento, foi possível traçar duas categorias, uma ligada ao ensino tradicional e a outra ao não tradicional. A intenção não foi a de polarizar, mas sim, mostrar dentre as contradições das falas dos sujeitos entrevistados, o equilíbrio necessário para definir e caracterizar a docência on-line.

Um grupo de professores trazia em suas falas uma concepção de docência on-line centrada na figura do professor e em sua relação com a tecnologia. A outra, não tradicional, trazia a fala de 
professores que viam importância na relação professor e aluno. Assim, é possível caracterizar, pela perspectiva dos entrevistados, que a docência on-line é construída sobre as TIC, sendo o AVA o ponto de convergência na relação aluno-professor-conteúdo. O professor tem um papel fundamental, pois parte dele a mediação entre aluno, tecnologia e conteúdo, além de ser ele um problematizador dentro do ambiente virtual.

Uma vez que ficaram claras as delimitações dessas duas categorias nas falas dos sujeitos, optou-se por considerá-las como elementos de classificação das respostas para o segundo grupo de questionamento do instrumento de pesquisa. Partiu-se, então, da idéia de que, por mais que ser ou não tradicional possa soar como aspectos diferentes, as duas categorias não foram vistas como antagônicas.

Ao analisar o primeiro conjunto de respostas daqueles mesmos sujeitos classificados na categoria de ensino tradicional, flagrou-se um processo, como tal inacabado e acontecendo, de uma mudança galgada para o ensino não tradicional. Isso, porém, não quer dizer que ela irá ou não realmente acontecer, pois é próprio de sua fugacidade. Assim, as principais características para a prática da docência on-line, a partir da perspectiva dos professores, podem ser agrupadas como aquelas que:

a) têm uma visão de sujeito, sendo capazes, por meio da empatia, entender o momento em que o aluno se encontra na relação ensino-aprendizagem, adaptando, quando necessário, à comunicação com ele;

b) sabem distinguir os limites entre o ensino presencial e os do ambiente on-line;

c) são conhecedoras das ferramentas disponíveis no AVA, bem como, sabem planejá-las e mediá-las conforme a variação dos estudantes e conteúdos;

d) apresentam sempre um feedback sobre as atividades e solicitações dos aprendizes;

e) pensam os processos avaliativos específicos e têm abertura para o trabalho em equipe, ou seja, a outros profissionais envolvidos com o processo, que vão desde os produtores dos conteúdos até os tutores.

Ao se caminhar para o desfecho desta reflexão, percebe-se que este estudo auxilia a compreensão do processo de formação de professores para a docência on-line. As concepções apresentadas pelos entrevistados provam que o desafio é bom e que frente à mudança do paradigma comunicacional, a docência no ensino superior precisa mobilizar todos os envolvidos no processo pedagógico - instituição, professor, aluno, etc. - para inserir as tecnologias on-line no ambiente de aprendizagem com pelo menos uma observação: o que vale na discussão e implantação desse processo não é apenas a tecnologia em si, mas um novo estilo de pedagogia no ambiente da era digital. 


\section{Referências}

ALMEIDA, C. T. O papel do pedagogo multimeios na utilização de recursos mediáticos colaborativos na modalidadede educação a distância. In: FARIA, E. T. (Org.). Educação presencial e virtual: espaços complementares essenciais na escola e na empresa. Porto Alegre: EDIPUCRS, 2006. p. 87-104.

ANASTASIOU, L. G. C. Metodologia do ensino superior: da prática docente a uma possível teoria pedagógica. Curitiba: IBPEX, 1998.

CALIXTO, A. C. Docência universitária: dimensões didáticas da prática pedagógica. 2012. Tese (Doutorado em Educação) - Universidade Federal de Uberlândia, Uberlândia, 2012.

CERVO, A. L.; BERVIAN, P. A. Metodologia científica. São Paulo: Makron Books, 1996.

FERREIRA, M. C. A.; SILVA, B. D. Docência online: tessitura pedagogia/comunicacional. In: CONGRESSO GALEGO-PORTUGUÊS DE PSICOPEDAGOGIA, 10., 2009, Braga. Actas... Braga: Universidade do Minho, 2009.

FLICK, U. Introdução à pesquisa qualitativa. Tradução Joice Elias Costa. 3. ed. Porto Alegre: Artmed, 2009.

GIL, A. C. O professor universitário. In: GIL, A. C. Metodologia do ensino superior. São Paulo: Atlas, 1997.

MALUSÁ, S.; FELTRAN, R. C. S. (Org.). A prática da docência universitária. São Paulo: Factash Editora, 2003.

MALUSÁ, S. O docente, o sistema socioeconômico atual, a ética, e os desafios à educação. Revista de Educação do Cogeime, ano 10, n. 18, p. 25-35, jun. 2001.

MASETTO, M. T. Competência pedagógica do professor universitário. São Paulo: Summus, 2003.
(Org.). Docência na universidade. Campinas: Papirus, 1998 .

MINAYO, M. C. de S. Pesquisa social: teoria, método e criatividade. 22. ed. Rio de Janeiro: Vozes, 2003.

MORAN, J. M. Contribuições para uma pedagogia da educação online. In: SILVA, M. (Org.). Educação online: teorias, práticas, legislação, formação corporativa. São Paulo: Loyola, 2003.

NETTO, C. Interatividade em ambientes virtuais de aprendizagem. In: FARIA, E. T; RAMOS, A. F. Educação presencial e virtual: espaços complementares essenciais na escola e na empresa. Porto Alegre: EDIPUCRS, 2006.

PÁDUA, E. M. M. Metodologia da pesquisa: abordagem técnico-prática. 10. ed. Campinas: Papirus, 2004.

PARREIRA JÚNIOR,W. M.; MALUSÁ, S.; OLIVEIRA, G. S. Docência universitária a distância: um estudo sobre o processo de ensino-aprendizagem. Revista Iberoamericana de Educación, n. 61/4, abr. 2013.

SACRAMENTO, M. C. A. F; SONNEVILLI, J. J.

Docência online: tecendo possibilidades para a prática educativa e para a pesquisa. Revista Práxis Educacional, Vitória da Conquista, v. 4, n. 4, p. 167-185, jan./jun. 2008.

SILVA, M.; CLARO, T. A docência online e a pedagogia da transmissão. Boletim Técnico Senac: a Revista da Educação Profissional, Rio de Janeiro, v. 33, n. 2, maio/ago. 2007.

TRIVIÑOS, A. N. S. Introdução à pesquisa em ciências sociais: a pesquisa qualitativa em educação. São Paulo: Atlas, 1987.

VILARINHO, L. R. G.; GANGA, L. L. S. Docência online: um desafio a enfrentar. Olhar de professor, Ponta Grossa, v. 12, n. 1, p. 95-109, 2009. 